\title{
Adaptive Sliding Model Control for Passive Electro- Hydraulic Servo Loading System with Backstepping
}

\author{
Geqiang $\mathrm{Li}^{1,2, *}$, Yongsheng $\mathrm{Gu}^{1}$ and Yuesong $\mathrm{Li}^{1}$ \\ ${ }^{1}$ Henan University of Science and Technology, Jianxi Borough 471003, Luoyang China \\ ${ }^{2}$ Collaborative Innovation Center of Machinery Equipment Advanced Manufacturing of Henan Province, Henan University of \\ Science and Technology, Luoyang 471003, Henan, China \\ ${ }^{*}$ Corresponding author
}

\begin{abstract}
This paper studies the problem of loading torque control for passive electro-hydraulic servo loading system with the external disturbance and parameter uncertainties. The state space model is established based on the nonlinear mathematical model of the system. Based on backstepping technique, an adaptive sliding mode backstepping control method is proposed for the system. By defining the sliding manifold and selecting a proper Lyapunov function, the final design of adaptive backstepping sliding mode controller is conducted and the stability of the controller is testified by the Lyapunov stability theory. The function of the controller was analyzed by comparative simulation study, which proves the feasibility and effectiveness of the proposed control strategy.
\end{abstract}

Keywords-backstepping; passive electro-hydraulic servo loading system; adaptive sliding mode control; parameter uncertainties; external disturbance

\section{INTRODUCTION}

Passive electro-hydraulic servo loading system is hardwarein-the-loop simulation equipment on the ground and is used to simulate the aerodynamic load of an aircraft during flight[1]. Because of the passive electro-hydraulic servo loading system not only bearing the load disturbance of the steering gear but also existing the influences of nonlinear characteristics and parameter uncertainties, it is difficult to achieve better control performance. In view of the problems above, scholars at home and abroad have put forward various methods to improve the loading performance of the system[2]. Parameter optimal feed forward compensation control is adopted[3]; A combined control strategy based on the auto disturbance rejection control technique and proportional integral syn-chronization error feedback correction is designed in [4]; a new adaptive backstepping control method based on command filtering is proposed, which to improve the performance of the system[5].

In this paper, the mathematical model of the passive electro-hydraulic servo loading system is reduced order processing by using the backstepping control theory, and combined with the sliding mode control. Finally, the adaptive backstepping sliding mode controller is designed. Compared with the tradional backstepping adaptive controller[6], the nesting problem caused by the mutual inclusion of parameter adaptive law and control input was effectively solved. The simulation results illustrate the effectiveness of the control method.

\section{MATHEMATICAL MOdel OF THE System}

The stiffness of connecting shaft should be similar to the torque sensor, the loading system belongs to a double degree of freedom driving force control system, and the output torque of the system is $T_{L}=G\left(\theta_{j}-\theta_{d}\right)$, The $\theta_{j}$ is the input angular displacement of the loading system, and the $\theta_{d}$ is the external disturbance input angular displacement. The state variable is defined as $\boldsymbol{\theta}_{\boldsymbol{j}}=\left[\theta_{j}, \dot{\theta}_{j}, \ddot{\theta}_{j}\right]^{T}$, where $\theta_{j 1}=\theta_{j}, \theta_{j 2}=\dot{\theta}_{j}, \theta_{j 3}=\ddot{\theta}_{j}$, the nonlinear state space model of passive electro-hydraulic servo loading system

$$
\left\{\begin{array}{l}
\dot{\theta}_{j 1}=\theta_{j 2}, \\
\dot{\theta}_{j 2}=\theta_{j 3}, \\
\dot{\theta}_{j 3}=a_{1} \theta_{j 1}+a_{2} \theta_{j 2}+a_{3} \theta_{j 3}+\left(1 / a_{4}\right) g\left(x_{v}\right) u_{m}+a_{5}, \\
y=T_{L}
\end{array}\right.
$$

where, $u_{m}$ is system input; $\mathrm{y}$ is system output; $a_{1}=-4 \beta_{e} C_{t m} G /\left(J V_{m}\right) ; a_{2}=-G / J-\left(4 \beta_{e} D_{m}^{2}+4 \beta_{e} C_{t m} B_{c}\right) /\left(J V_{m}\right)$;

$a_{3}=-B_{c} / J-4 \beta_{e} C_{t m} / V_{m} ; a_{4}=J V_{m} \sqrt{\rho} /\left(4 D_{m} \beta_{e} C_{d} w K_{a} G_{s v}\right) ;$

$a_{5}=G \dot{\theta}_{d} / J+4 \beta_{e} C_{t m} G \theta_{d} /\left(J V_{m}\right) ; g\left(x_{v}\right)=\sqrt{P_{s}-P_{L} \operatorname{sgn}\left(x_{v}\right)}$

where, $C_{d}$ is valve port flow coefficient; $w$ is area gradient for servo valve; $x_{v}$ is opening degree of servo valve eleent; $P_{S}$ is source pressure for oil; $P_{L}$ is loading pressure; $\rho$ is hydraulic oil density; $\beta_{\mathrm{e}}$ is elasticity modulus of effective volume; $J$ is rotational inertia of motor; $B_{c}$ is viscous damping coefficient of motor; $T_{L}$ is system output torque; $\mathrm{G}$ is torsional stiffness of the connecting shaft; $\theta_{\mathrm{d}}$ is angular displacement of load; $K_{a}$ is servo amplifier gain; $G_{s v}$ is servo valve gain; $D_{m}$ is theoretical displacement of motor; $\theta_{j}$ is angular displacement of motor; $C_{t m}$ is overall leakage coefficient of motor; $V_{m}$ is total volume of motor chamber and pipeline. 


\section{DESIGN OF CONTROLLER}

The final output error of the system is defined as $e_{0}=T_{L}-T_{L i n}=G\left(\theta_{j 1}-\theta_{j d 1}\right)$.The load torque output accuracy in the system is determined by $\theta_{j 1}$ and $\theta_{j d 1}$, all errors are defined.

$$
\begin{aligned}
& e_{1}=\theta_{j 1}-\theta_{j d 1} \\
& e_{2}=\theta_{j 2}-\theta_{j d 2} \\
& e_{3}=\theta_{j 3}-\theta_{j d 3}
\end{aligned}
$$

where, $T_{L i n}$ is the system command input; $\theta_{j i}(i=1,2,3)$ is the actual value and $\theta_{j d i}(i=1,2,3)$ is the expected value of the system state variables. The following is the derivation of the virtual control of each subsystem, $f_{i}(i=1,2,3)$ is the controller adjustment coefficient.

Step 1: The derivative of (2) with (3) gives

$$
\dot{e}_{1}=\dot{\theta}_{j 1}-\dot{\theta}_{j d 1}=e_{2}+\theta_{j d 2}-\dot{\theta}_{j d 1}
$$

The Lyapunov function is chosen as

$$
V_{1}=1 / 2 e_{1}^{2} \geq 0
$$

The virtual control is as follows

$$
\theta_{j d 2}=\dot{\theta}_{j d 1}-f_{1} e_{1}
$$

The derivative of (6) with (7) gives

$$
\dot{V}_{1}=-f_{1} e_{1}^{2}+e_{1} e_{2}
$$

Step 2: Substituting (7) into (3) gives

$$
e_{2}=\theta_{j 2}-\dot{\theta}_{j d 1}+f_{1} e_{1}
$$

The Lyapunov function is chosen as

$$
V_{2}=1 / 2 e_{1}^{2}+1 / 2 e_{2}^{2} \geq 0
$$

The virtual control is as follows

$$
\theta_{j d 3}=-e_{1}+\dot{\theta}_{j d 2}-f_{2} e_{2}
$$

The derivative of (10) with (11)gives

$$
\dot{V}_{2}=-f_{1} e_{1}^{2}-f_{2} e_{2}^{2}+e_{2} e_{3}
$$

Step 3: Sliding mode control is used and the sliding manifold is defined as

$$
s=c_{1} e_{1}+c_{2} e_{2}+e_{3}
$$

where, $c_{1}, c_{2}$ is normal number, differentiating (13) gives

$$
\begin{gathered}
\dot{s}=c_{1}\left(\theta_{j 2}-\dot{\theta}_{j d 1}\right)+c_{2}\left(\theta_{j 3}-\dot{\theta}_{j d 2}\right)+a_{1} \theta_{j 1}+ \\
a_{2} \theta_{j 2}+a_{3} \theta_{j 3}+\left(1 / a_{4}\right) g\left(x_{v}\right) u_{m}+a_{5}-\dot{\theta}_{j d 3}
\end{gathered}
$$

To avoid the design of adaptive law, $\hat{a}_{4}$ contains $u_{m}$, the Lyapunov function is chosen as

$$
V_{3}=V_{2}+1 / 2 a_{4} s^{2} \geq 0
$$

The derivative of (15) gives

$$
\begin{gathered}
\dot{V}_{3}=-f_{1} e_{1}^{2}-f_{2} e_{2}^{2}+e_{2} e_{3}+s\left[c _ { 1 } a _ { 4 } \left(\theta_{j 2}-\right.\right. \\
\left.\dot{\theta}_{j d 1}\right)+c_{2} a_{4}\left(\theta_{j 3}-\dot{\theta}_{j d 2}\right)+\tau_{1} \theta_{j 1}+ \\
\left.\tau_{2} \theta_{j 2}+\tau_{3} \theta_{j 3}+g\left(x_{v}\right) u_{m}+\tau_{4}-a_{4} \dot{\theta}_{j d 3}\right]
\end{gathered}
$$

where, $\tau_{1}=a_{1} a_{4}, \tau_{2}=a_{2} a_{4}, \tau_{3}=a_{3} a_{4}, \tau_{4}=a_{4} a_{5}$, $\boldsymbol{\tau}=\left[\tau_{1}, \tau_{2}, \tau_{3}, \tau_{4}\right]^{T}$.

Define $\tilde{\boldsymbol{\tau}}=\boldsymbol{\tau}-\hat{\boldsymbol{\tau}}, \tilde{a}_{4}=a_{4}-\hat{a}_{4}$, the estimated values of $\boldsymbol{\tau}, a_{4}$ are $\hat{\boldsymbol{\tau}}, \hat{a}_{4}$.

The Lyapunov function of system is chosen as

$$
\begin{aligned}
& V=V_{3}+\frac{1}{2} \lambda_{1} \tilde{\tau}_{1}^{2}+\frac{1}{2} \lambda_{2} \tilde{\tau}_{2}^{2}+ \\
& \frac{1}{2} \lambda_{3} \tilde{\tau}_{3}^{2}+\frac{1}{2} \lambda_{4} \tilde{\tau}_{4}^{2}+\frac{1}{2} \lambda_{5} \tilde{a}_{4}^{2} \geq 0
\end{aligned}
$$

where, $\quad \lambda_{i}>0(i=1,2,3,4,5)$ is the parameter adaptive law adjustment coefficient.

$$
\begin{aligned}
\dot{V}= & -f_{1} e_{1}^{2}-f_{2} e_{2}^{2}+e_{2} e_{3}+s\left[c_{1} a_{4}\left(\theta_{j 2}-\dot{\theta}_{j d 1}\right)+\right. \\
& c_{2} a_{4}\left(\theta_{j 3}-\dot{\theta}_{j d 2}\right)+\tau_{1} \theta_{j 1}+\tau_{2} \theta_{j 2}+\tau_{3} \theta_{j 3}+ \\
& \left.g\left(x_{v}\right) u_{m}+\tau_{4}-a_{4} \dot{\theta}_{j d 3}\right]+\lambda_{1} \tilde{\tau}_{1}\left(-\dot{\hat{\tau}}_{1}\right)+\lambda_{2} \tilde{\tau}_{2}\left(-\dot{\hat{\tau}}_{2}\right)+ \\
& \lambda_{3} \tilde{\tau}_{3}\left(-\dot{\hat{\tau}}_{3}\right)+\lambda_{4} \tilde{\tau}_{4}\left(-\dot{\hat{\tau}}_{4}\right)+\lambda_{5} \tilde{a}_{4}\left(-\dot{\hat{a}}_{4}\right)
\end{aligned}
$$


Finally, the adaptive backstepping sliding mode controller is designed as follows.

$$
\begin{aligned}
u_{m}= & \frac{1}{g\left(x_{v}\right)}\left[-c_{1} \hat{a}_{4}\left(\theta_{j 2}-\dot{\theta}_{j d 1}\right)-c_{2} \hat{a}_{4}\left(\theta_{j 3}-\dot{\theta}_{j d 2}\right)\right. \\
& \left.-\hat{\tau}_{1} \theta_{j 1}-\hat{\tau}_{2} \theta_{j 2}-\hat{\tau}_{3} \theta_{j 3}-\hat{\tau}_{4}+\hat{a}_{4} \dot{\theta}_{j d 3}-f_{3} s\right]
\end{aligned}
$$

The adaptive law of parameter variation is

$$
\left\{\begin{array}{l}
\dot{\hat{\tau}}_{1}=\frac{1}{\lambda_{1}} s \theta_{j 1}, \quad \dot{\hat{\tau}}_{2}=\frac{1}{\lambda_{2}} s \theta_{j 2}, \quad \dot{\hat{\tau}}_{3}=\frac{1}{\lambda_{3}} s \theta_{j 3}, \quad \dot{\hat{\tau}}_{4}=\frac{1}{\lambda_{4}}|s| \\
\dot{\hat{a}}_{4}=\frac{1}{\lambda_{5}}\left[c_{1} s\left(\theta_{j 2}-\dot{\theta}_{j d 1}\right)+c_{2} s\left(\theta_{j 3}-\dot{\theta}_{j d 2}\right)-s \dot{\theta}_{j d 3}\right]
\end{array}\right.
$$

The stability condition of the system can be obtained by the analysis of the Lyapunov function. Substituting(19) into (18) gives

$$
\dot{V} \leq-f_{1} e_{1}^{2}-f_{2} e_{2}^{2}+e_{2} e_{3}-f_{3} s^{2}=-\boldsymbol{E}^{T} \boldsymbol{Q E}
$$

where, $\boldsymbol{E}=\left[e_{1}, e_{2}, e_{3}\right]^{T}$

$$
\boldsymbol{Q}=\left[\begin{array}{lll}
f_{1}+f_{3} c_{1}^{2} & c_{1} c_{2} f_{3} & c_{1} f_{3} \\
c_{1} c_{2} f_{3} & f_{2}+f_{3} c_{2}^{2} & c_{2} f_{3}-\frac{1}{2} \\
c_{1} f_{3} & c_{2} f_{3}-\frac{1}{2} & f_{3}
\end{array}\right]
$$

To ensure that the system is asymptotically stable, the parameters $c_{1}, c_{2}, f_{1}, f_{2}$, and $f_{3}$ in the ABSC controller must satisfy the inequality

$$
\left\{\begin{array}{l}
f_{1}>0, f_{2}>0, f_{3}>0, c_{1}>0, c_{2}>0 \\
f_{1} f_{2}+f_{1} f_{3} c_{2}^{2}+f_{2} f_{3} c_{1}^{2}>0 \\
f_{1} f_{2} f_{3}+f_{1} f_{3} c_{2}-\left(f_{1}+f_{3} c_{1}^{2}\right) / 4>0
\end{array}\right.
$$

Define $W=\boldsymbol{E}^{T} \boldsymbol{Q E}$. By formula (21), $\dot{V} \leq-W$ because $e_{1}, e_{2}, e_{3}, \tilde{\tau}_{1}, \tilde{\tau}_{2}, \tilde{\tau}_{3}, \tilde{\tau}_{4}$, and $\tilde{a}_{4}$ are bounded, so $V$ is bounded. According to the Barbalat lemma, when $t \rightarrow \infty, e_{i}(i=1,2,3) \rightarrow 0$. That is, the entire system is asymptotically stable.

\section{CONTROLler SimUlation ANALysis}

According to the derivation of the ABSC controller, the nonlinear control system block diagram, as shown in Figure 1,

\begin{tabular}{|c|c|c|}
\hline Parameter & Name & Value \\
\hline$J$ & $\begin{array}{l}\text { Equivalent load inertia } \\
\text { of motor }\end{array}$ & $1.01 \times 10^{-3} \mathrm{~kg} \cdot \mathrm{m}^{2}$ \\
\hline$D_{m}$ & $\begin{array}{l}\text { Theoretical } \\
\text { displacement of motor }\end{array}$ & $4.40 \times 10^{-5} \mathrm{~m}^{3} \cdot \mathrm{rad}^{-1}$ \\
\hline$V_{m}$ & $\begin{array}{l}\text { Effective volume of } \\
\text { the system }\end{array}$ & $4.00 \times 10^{-4} \mathrm{~m}^{3}$ \\
\hline$C_{t m}$ & leakage coefficient & $4.00 \times 10^{-12} \mathrm{~m}^{5} \cdot(\mathrm{N} \cdot \mathrm{s})^{-1}$ \\
\hline$\beta_{e}$ & $\begin{array}{l}\text { Elasticity modulus of } \\
\text { effective volume }\end{array}$ & $6.90 \times 10^{8} \mathrm{~N} \cdot \mathrm{m}^{-2}$ \\
\hline$w$ & $\begin{array}{l}\text { gradient for servo } \\
\text { valve }\end{array}$ & $3.14 \times 10^{-2} \mathrm{~m}$ \\
\hline$C_{d}$ & $\begin{array}{l}\text { valve port flow coe- } \\
\text { fficient }\end{array}$ & $6.10 \times 10^{-1}$ \\
\hline G & $\begin{array}{l}\text { Stiffness of connect- } \\
\text { ing shaft }\end{array}$ & $3.5 \times 10^{3} \mathrm{~N} \cdot \mathrm{m} \cdot \mathrm{rad}^{-1}$ \\
\hline$B_{c}$ & $\begin{array}{l}\text { viscous damping co- } \\
\text { efficient }\end{array}$ & $8.00 \mathrm{~N} \cdot \mathrm{m} \cdot\left(\mathrm{rad} \cdot \mathrm{s}^{-1}\right)^{-1}$ \\
\hline$G_{s v}$ & servo valve gain & $3.25 \times 10^{-2} \mathrm{~m} / \mathrm{A}$ \\
\hline
\end{tabular}
can be obtained. The parameters of the controller are selected as $f_{1}=43, f_{2}=17, f_{3}=32, c_{1}=0.1, c_{2}=0.2, \lambda_{1}=4 \times 10^{-10}, \lambda_{2}=2 \times$ $10^{-12}, \quad \lambda_{3}=1 \times 10^{-9}, \lambda_{4}=3 \times 10^{-6}, \lambda_{5}=1.5 \times 10^{-3}$. See Table 1 for the main parameters of the system.
TABLE I. SIMULATION PARAMETER TABLE

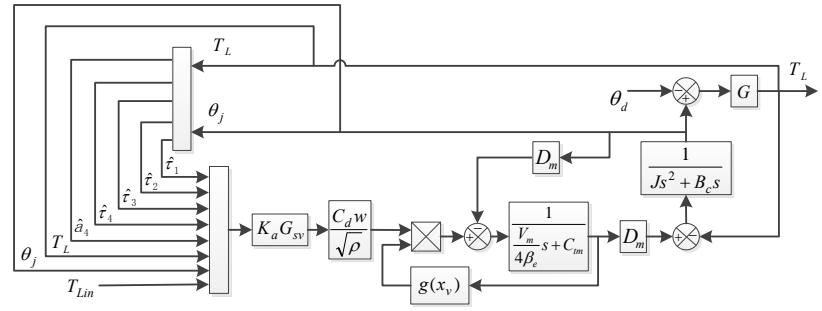

FIGURE I. BLOCK DIAGRAM OF NONLINEAR CONTROL SYSTEM

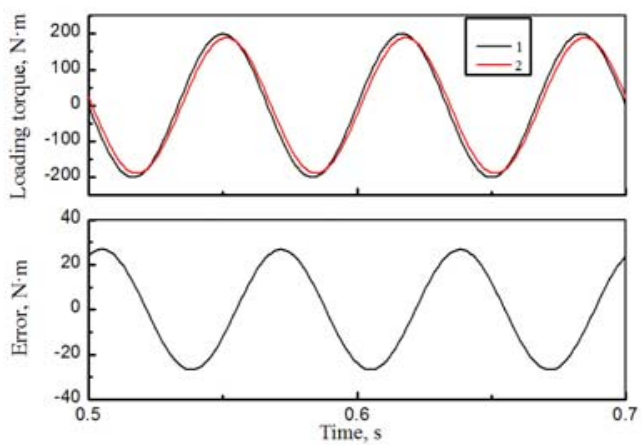

(a) Torque output with PID control

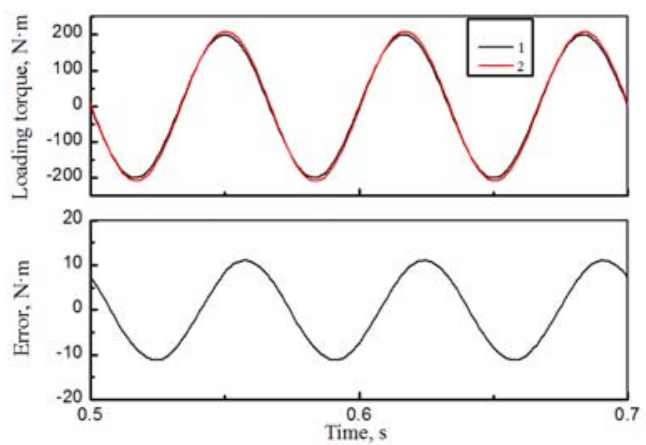

(b) Torque output with ABSC control

FIGURE II. SIMULATION CURVES OF LINEAR LOADING 
To test the effectiveness of the designed controller, according to various loading conditions, the simulation analysis of the ABSC controller and PID contoller is conducted as follows. The process is sinusoidal loading. In Figure 2, Figure 3 , and Figure 4, curve 1 is the command signal, curve 2 is the output of the controller.

Figure 2 is the output torque and error curve under the linear loading, of which the loading system is $200 \mathrm{~N} . \mathrm{m}$, the bearing system amplitude is about $\pm 5^{\circ}$, the frequency is $15 \mathrm{~Hz}$. As shown, the effect of PID controller is poor when frequency is $15 \mathrm{~Hz}$, the error is $26 \mathrm{~N} . \mathrm{m}$, fail to track the performance requirements of double-ten indicators; the amplitude tracking is improved obviously when using the ABSC controller, the error is only $8 \mathrm{~N} . \mathrm{m}$. The inhibition of the ABSC controller in terms of the extra torque interference are superior to those of the PID controller.

The nonlinear load simulation is shown in Figure 3. For a load torque of $120 \mathrm{~N} \cdot \mathrm{m}$ with a frequency of $15 \mathrm{~Hz}$, the bearing system has an amplitude of 2 degrees with a frequency of 10 Hz. As shown in Figure 3, when using the PID controller, the output torque curve shows bias, with the curve showing the "beating" state, and there is a certain lag phase. In contrast, the ABSC controller does not show the phenomenon above, so the ABSC controller has a good control effect on the nonlinear load.

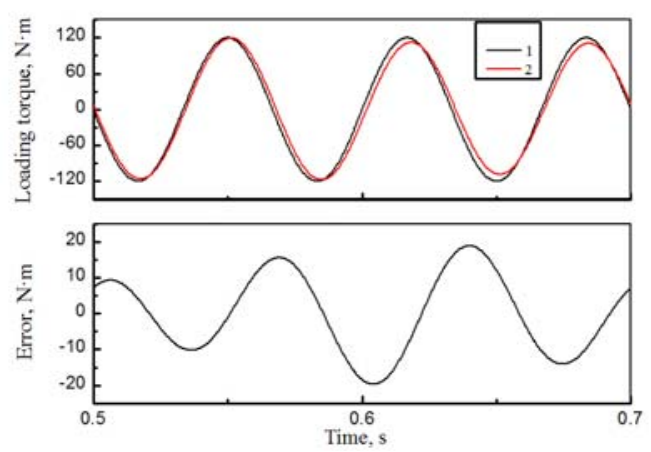

(a) Torque output with PID control

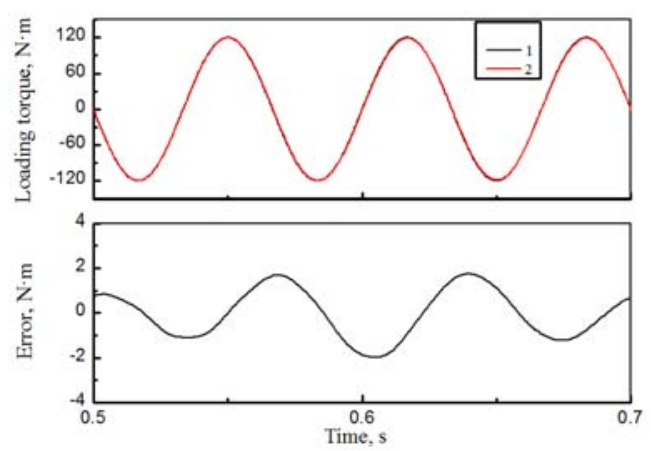

(b) Torque output with ABSC control

FIGURE III. SIMULATION CURVES OF NONLINEAR LOADING

To verify the performance of the disturbance rejection controller design for the outside signal, for $T_{L}=60 \mathrm{~N} \cdot \mathrm{m}$, the bearing system amplitude is $1^{\circ}$ with a sine wave frequency of
$15 \mathrm{~Hz}$, and the output torque is appended to the end of the 20 $\mathrm{N} \cdot \mathrm{m}$ amplitude, with a period of $0.8 \mathrm{~s}$, a width of $0.4 \mathrm{~s}$, and wave signal interference. The simulation results are shown in Figure 4 , the system is disturbed by the outside square wave signal at $0.4 \mathrm{~s}$. The ABSC controller can inhibit the interference better than the PID controller, so the ABSC controller has strong inhibition ability for external disturbances.
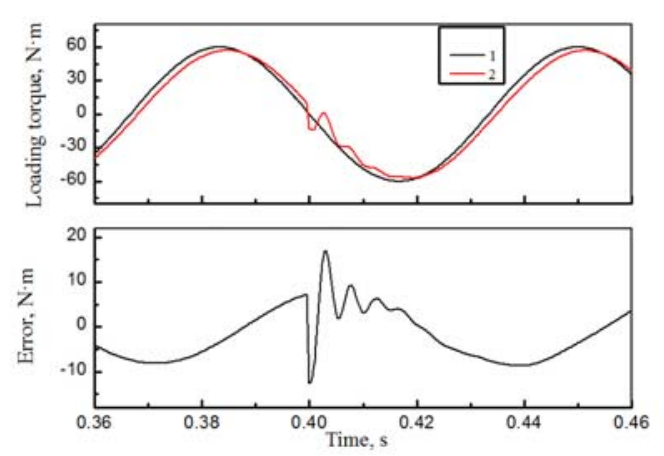

(a) Torque output with PID control
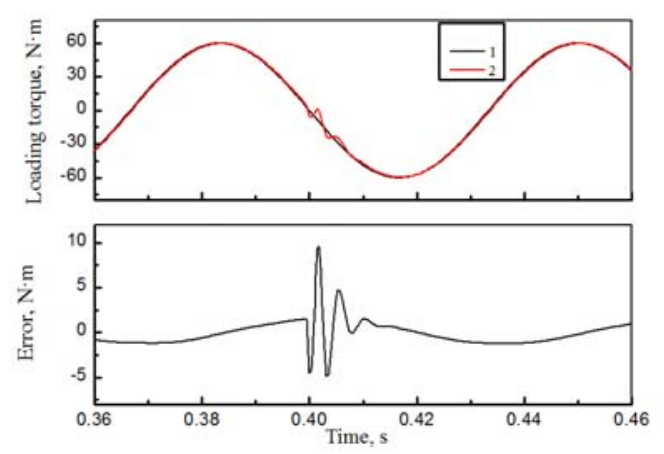

(b) Torque output with ABSC control

FIGURE IV. SIMULATION CURVES WITH SQUARE WAVE DISTURB ON LOADING SYSTEM

\section{CONCLUSION}

Aimed at the problem of the passive electro-hydraulic servo loading system with the external disturbance and parameter uncertainties, the adaptive backstepping sliding mode control strategy is proposed. The strategy not only overcoming the influences of external disturbance and uncertainty parameters but also solving the problem of the control quantity and the adaptive law being nested. The simulation results show that the ABSC controller has a better control effect and can effectively improve the loading performance of the system under various conditions of loading and external disturbance.

\section{ACKNOWLEDGMENT}

This study is supported by the National Natural Science Foundation of China (51175148).

\section{REFERENCES}

[1] WANG C W, JIAO Z X, LUO C J, An improved velocity synchronization control on electro-hydraulic load simulator[J]. Acta Aeronautica ET Astronautica Sinica2012, 09:1717-1725. 
[2] HAO J J. Application of dual value in electro-hydraulicsimulator[J]. China Mechanical Engineering, 2002,13(10): 814-816.

[3] OUYANG X P, LI F, ZHU Y, et al. Nonlinear optimal feedforward compensation controller for heavy load aviation load simulator[J]. Acta Aeronautica ET Astronautica Sinica, 2016, 02:669-679.

[4] GUO D, FU Y L, LU N, et al. Application of ADRC technology in electro-hydraulic force servo system [J]. Journal of Beijing University of Aeronautics and Astronautics, 2013, 01:115-119.

[5] FANG Y M,SHI S L,LI J X, et al. Adaptive backstepping control for electro-hydraulic servo system with input saturation based on command filter[J]. Electric Machines and Control, 2013, 09:105-110.

[6] CAO J, ZHANG B, ZHAO K D. Backstepping control of passive force control system with parameter uncertainties[J]. Journal of Harbin Institute of Technology, 2010, 07:1071-1075. 